\title{
Factors associated with distant metastasis in pediatric thyroid cancer: evaluation of the SEER database
}

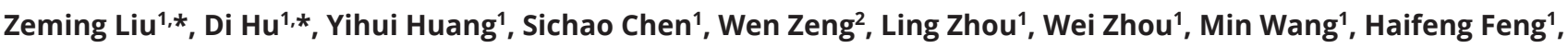 \\ Wei Wei ${ }^{3}$, Chao Zhang ${ }^{4}$, Danyang Chen ${ }^{1}$ and Liang Guo ${ }^{1}$ \\ 'Department of Plastic Surgery, Zhongnan Hospital of Wuhan University, Wuhan, China \\ 2Department of Ophthalmology, Zhongnan Hospital of Wuhan University, Wuhan, China \\ ${ }^{3}$ Department of Pediatrics, St John Hospital and Medical Center, Detroit, Michigan, USA \\ ${ }^{4}$ Department of Cardiovascular Surgery, Union Hospital, Tongji Medical College, Huazhong University of Science and Technology, Wuhan, China \\ Correspondence should be addressed to L Guo or D Chen: guoliangwhzn@163.com or chendanyangwhzn@163.com \\ *(Z Liu and D Hu contributed equally to this work)
}

\begin{abstract}
Objectives: Controversies regarding factors associated with distant metastasis in pediatric thyroid cancer remain among the scientific community. The aim of this study was to investigate factors influencing distant metastasis in pediatric thyroid cancer. Methods: We reviewed 1376 patients (aged 2 to 18 years) with thyroid cancer treated between 2003 and 2014. Data collected and analyzed included sex, race, age at diagnosis, year of diagnosis, pathological type, number of tumor foci, tumor extension, T-stage, N-stage, surgical procedure and radiation. Univariate and multivariate analyses were conducted to evaluate factors influencing distant metastasis of pediatric thyroid cancer.

Results: In the univariate analysis, factors influencing distant metastasis of thyroid cancer were age at diagnosis $(P<0.001), \mathrm{N}$-stage $(P<0.001)$, number of tumor foci $(P=0.003)$, tumor extension $(P<0.001)$ and T-stage (T1 vs T2 $(P=0.803)$, T3 $(P<0.001)$ and T4 $(P<0.001)$ ). In multivariate analysis, factors influencing distant metastasis of thyroid cancer were age at diagnosis $(P=0.001), \mathrm{N}$-stage $(P<0.001)$ and T-stage (T1 vs T3 $(P=0.036)$ and T4 $(P<0.001))$. Sex, race, year of diagnosis, pathological type, number of tumor foci, tumor extension, surgical procedure and radiation had no significant influence on distant metastasis (all $P>0.05$ ). Furthermore, according to chi-squared test, younger pediatric thyroid cancer patients with higher $\mathrm{T}$ - and $\mathrm{N}$-stages are more likely to have distant metastasis.

Conclusion: Age at diagnosis, T-stage and $\mathrm{N}$-stage influence distant metastasis of thyroid cancer patients aged 2 to 18 years; accordingly, more radical treatments may need to be used for patients with those risk elements.
\end{abstract}

\author{
Key Words \\ - endocrine malignant \\ tumor \\ - thyroid cancer \\ - children \\ - distant metastasis
}

Endocrine Connections (2019) 8, 78-85

\section{Introduction}

Thyroid carcinoma is the most common malignant tumor in the endocrine system (1) and mainly consists of papillary thyroid carcinoma, follicular thyroid carcinoma, undifferentiated thyroid carcinoma and medullary thyroid carcinoma. Among pediatric patients, papillary thyroid carcinoma and follicular thyroid cancer account for more than $90 \%$ (2) of all childhood cases. However, medullary thyroid cancer, poorly differentiated tumors

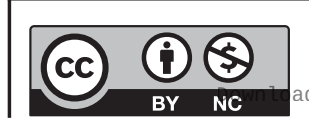

This work is licensed under a Creative Commons Attribution-NonCommercial 4.0 International License. ded from Bioscientifica.com at 04/26/2023 06:26:44AM 
and undifferentiated (anaplastic) thyroid carcinomas are rare in young patients (3).

According to the Surveillance, Epidemiology and End Results (SEER) program, cases of thyroid cancer in individuals aged 2 to 18 years represent $1.44 \%$ of all diagnosed thyroid malignancies. Hence, there are more published studies concerning thyroid cancer in adults than in children. However, recommendations for adults may not be appropriate for children, for whom thyroid cancer characteristics slightly differ from those in adults. Compared with adult patients, the incidence and mortality rate of pediatric thyroid cancer is low; moreover, pediatric differentiated thyroid cancer has a higher rate of distant metastasis (4). Thus, there seems to be a significant need for relevant studies in children and adolescents with thyroid tumors based on large, population-level data (5).

Thyroid nodules can be discovered by patients themselves or by a physician during a routine physical examination; they may also be observed incidentally during imaging for organs such as brain and lung. Furthermore, distant metastasis can be found in pediatric thyroid patients even during the early course of the disease. Specifically, according to previous studies, the extent of cervical disease at the time of diagnosis correlates with risk for distant metastasis, which may require additional treatment, and is also considered during postoperative staging, which allows for stratification of patients who may or may not benefit from further therapy (6). Thus, more comprehensive information regarding distant metastasis of childhood thyroid nodules may help to develop recommendations to improve rates of early diagnosis. Therefore, we investigated factors influencing distant metastasis in pediatric patients with thyroid cancer to inform the management of pediatric patients with suspected and known distant metastases.

\section{Materials and methods}

\section{SEER database and eligible study population}

The data for the present study was derived from the SEER Program (SEER 18) of the National Cancer Institute; SEER, which is supported by the Surveillance Research Program (SRP) in NCI's Division of Cancer Control and Population Sciences (DCCPS), is an openly accessible database, and it currently collects and publishes cancer incidence and survival data from population-based cancer registries covering approximately $34.6 \%$ of the US population. This study was approved by the Ethics Committee of Zhongnan Hospital of Wuhan University. We examined the data from 1376 cases of pediatric thyroid cancer patients aged 2 to 18 years treated between 2004 and 2013. Evaluated characteristics included demographic (age at diagnosis, sex, race), clinical (tumor size and extent, operation type, lymph node involvement, distant metastasis) and prognostic (cancer-specific cause of death and overall cause of death) data. Informed consent was obtained from each patient after fully explaining of the purpose and nature of all procedures used, and patient records were anonymized and de-identified prior to the analysis.

Data were categorized as follows: sex (male, female), race (white, black, other), age at diagnosis ( $\leq 15,>15$ years), year of diagnosis (2004-2008, 2009-2013), tumor size ( $\leq 10$, $10-20,>20-40,>40 \mathrm{~mm}$ ), T-stage (tumor size/extension evaluation: T1, T2, T3, T4), N-stage (regional lymph node metastasis status: N0, N1) and radiation (none or refused, radiation beam or radioactive implants, radioisotopes or radiation beam+isotopes/implants). In our study, we considered all subtypes of papillary and follicular cancer as papillary thyroid cancer and follicular thyroid cancer, respectively. To assure accuracy of the results, missing or unknown data were considered as missing values.

\section{Statistical analysis}

Descriptive statistics are presented as summarized data. Continuous variables and discrete variables are reported as proportions. Univariate analysis of factors such as age, sex and other clinicopathological parameters were performed using binary logistic regression. Multivariate analysis of factors such as age at diagnosis, $\mathrm{N}$-stage and M-stage was carried out using binary logistic regression and the chisquared test. We used the Kaplan-Meier method for the following variables: age at diagnosis, $\mathrm{N}$-stage and T-stage. All statistical analyses were performed using SPSS software (version 22.0, Chicago, IL, USA). $P$ values $<0.05$ were considered statistically significant.

\section{Results}

Patient characteristics are shown in Table 1. Mean age at diagnosis was 15.33 years, including 1126 (81.8\%) girls and $250(18.2 \%)$ boys. Papillary thyroid cancer incidence was higher than follicular thyroid cancer incidence (papillary to follicular, 10.4:1). Extension was present in 22.7\%, and there were 13 cases of pulmonary metastasis. Based on M-stage, M0 and M1 were observed in 1324 (96.2\%), $52(3.8 \%)$ cases, respectively. 
Table 1 Demographics and clinical characteristics of pediatric thyroid cancer patients.

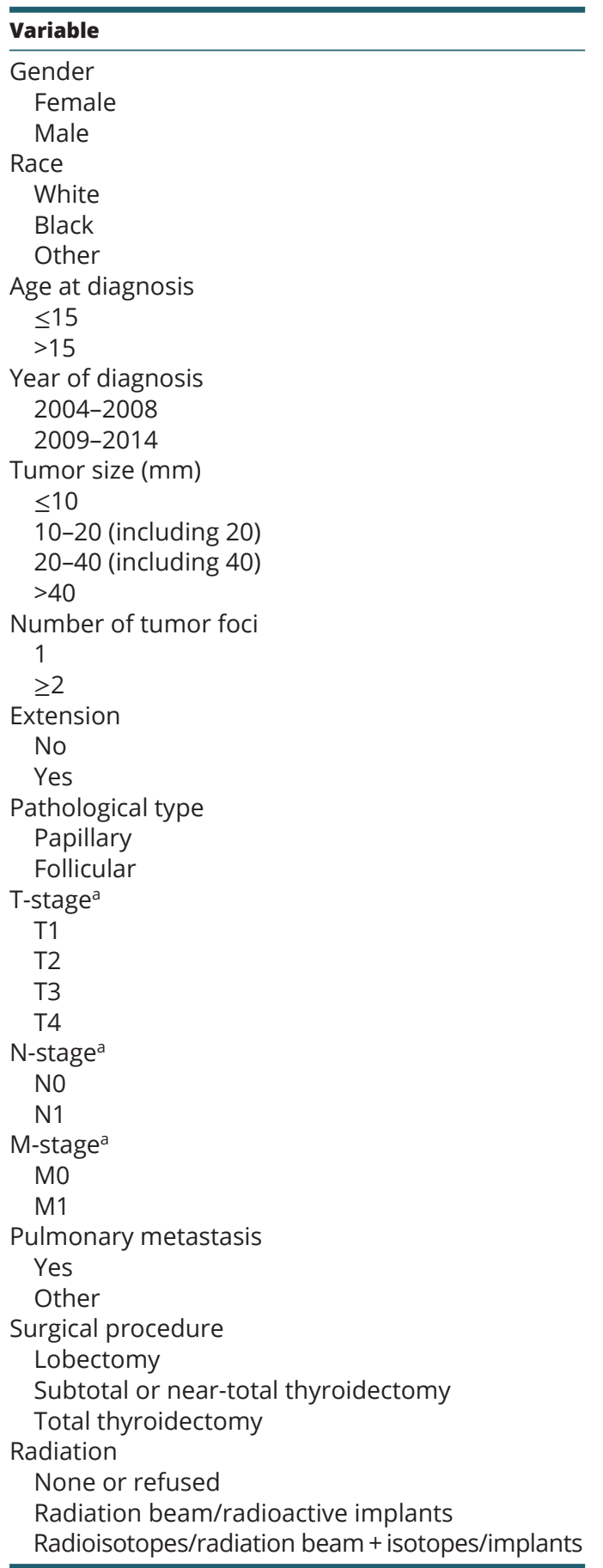

$\frac{n(\%)}{}$
$1126(81.8)$
$250(18.2)$
$1145(84.9)$
$63(4.7)$
$140(10.4)$

$565(41.1)$

$811(58.9)$

$586(42.6)$

$790(57.4)$

$233(18.3)$

$358(28.2)$

$463(36.5)$

$216(17.0)$

$822(61.6)$

$512(38.4)$

1047 (77.3)

308 (22.7)

1253 (91.2)

$121(8.8)$

518 (39.1)

351 (26.5)

390 (29.5)

65 (4.9)

728 (53.3)

638 (46.7)

1324 (96.2)

52 (3.8)

$13(0.9)$

$1363(99.1)$

$128(9.5)$

46 (3.4)

1171 (87.1)

458 (34.2)

$11(0.8)$

$871(65.0)$

aT-stage: describes the size of the original (primary) tumor and whether it has invaded nearby tissue; N-stage: describes nearby (regional) lymph nodes that are involved; M-stage: describes distant metastasis (spread of cancer from one part of the body to another).

In patients with distant metastasis, the mean age at diagnosis was 16.37 years, including $40(76.9 \%)$ girls and $12(23.1 \%)$ boys. The papillary to follicular ratio was
Table 2 Demographics and clinical characteristics of pediatric thyroid cancer patients with distant metastasis.

\begin{tabular}{|c|c|}
\hline Variable & $\boldsymbol{n}(\%)$ \\
\hline \multicolumn{2}{|l|}{ Gender } \\
\hline Female & 40 (76.9) \\
\hline Male & $12(23.1)$ \\
\hline \multicolumn{2}{|l|}{ Race } \\
\hline White & $42(80.8)$ \\
\hline Black & $6(11.5)$ \\
\hline Other & $4(7.7)$ \\
\hline \multicolumn{2}{|c|}{ Age at diagnosis } \\
\hline$\leq 15$ & $38(73.1)$ \\
\hline$>15$ & $14(26.9)$ \\
\hline \multicolumn{2}{|c|}{ Year of diagnosis } \\
\hline 2004-2008 & $22(42.3)$ \\
\hline 2009-2014 & 30 (57.7) \\
\hline
\end{tabular}

Tumor size (mm)

$\leq 10$

$1(2.7)$

10-20 (including 20) $7(18.9)$

20-40 (including 40) $10(27.0)$

$>40$

19 (51.4)

Number of tumor foci

1

$\geq 2$

Extension

No

Yes

Pathological type

Papillary

Follicular

19 (40.4)

$28(59.6)$

$15(32.6)$

$31(67.4)$

$50(96.2)$

2 (3.8)

T-stage

T1

$\mathrm{T} 2$

$5(10.2)$

4 (8.2)

T3

$\mathrm{T} 4$

$\mathrm{N}$-stage

NO

$23(46.9)$

$17(34.7)$

1 (2.0)

N1

49 (98.0)

Pulmonary metastasis

Yes

$13(25.0)$

Other

$39(75.0)$

Surgical procedure

Lobectomy

Subtotal or near-total thyroidectomy

$1(2.0)$

$3(6.0)$

Total thyroidectomy

Postoperative radioiodine treatment $(\mathrm{mCi})$

None or refused

$46(92.0)$

Radiation beam/radioactive implants

$8(15.4)$

Radioisotopes/radiation beam + isotopes/implants

$1(1.9)$

$43(82.7)$

25:1. Compared with the data from all pediatric thyroid cancer patients, characteristics were similar, excluding extrathyroidal invasion, which was present in $67.4 \%$ of patients (Table 2).

In the univariate analysis, age of diagnosis, number of tumor foci, tumor extension, $\mathrm{N}$-stage and T-stage were significant prognostic factors. Multivariate analysis using binary logistic regression found that age at diagnosis, $\mathrm{N}$-stage and M-stage were independent prognostic

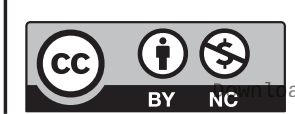

This work is licensed under a Creative Commons Attribution-NonCommercial 4.0 International License. 
Table 3 Odds ratios for distant metastasis: outcome of univariate logistics regression.

\begin{tabular}{|c|c|c|c|}
\hline \multirow[b]{2}{*}{ Covariate } & \multirow[b]{2}{*}{ Level } & \multicolumn{2}{|c|}{ Distant metastasis } \\
\hline & & Odds ratio $(95 \% \mathrm{Cl})$ & $P$-value \\
\hline \multirow[t]{2}{*}{ Gender } & Female & Ref & \\
\hline & Male & $1.37(0.71-2.65)$ & 0.351 \\
\hline \multirow[t]{3}{*}{ Race } & White & Ref & \\
\hline & Black & $2.76(1.13-6.78)$ & 0.026 \\
\hline & Other & $0.77(0.27-2.19)$ & 0.627 \\
\hline Age at diagnosis & & 0.83 (0.77-0.89) & $<0.001$ \\
\hline \multirow[t]{2}{*}{ Year of diagnosis } & 2004-2008 & Ref & \\
\hline & 2009-2013 & $1.01(0.58-1.77)$ & 0.976 \\
\hline \multirow[t]{2}{*}{ Pathological type } & Papillary & Ref & \\
\hline & Follicular & $0.40(0.10-1.68)$ & 0.213 \\
\hline \multirow[t]{2}{*}{ Number of tumor foci } & 1 & Ref & \\
\hline & $\geq 2$ & $2.45(1.35-4.43)$ & 0.003 \\
\hline \multirow[t]{2}{*}{ Extension } & $\overline{N o}$ & Ref & \\
\hline & Yes & 7.70 (4.10-14.47) & $<0.001$ \\
\hline \multirow[t]{4}{*}{ T-stage } & $\mathrm{T} 1$ & Ref & \\
\hline & $\mathrm{T} 2$ & $1.18(0.32-4.44)$ & 0.803 \\
\hline & T3 & $6.43(2.42-17.07)$ & $<0.001$ \\
\hline & $\mathrm{T} 4$ & $36.34(12.84-102.82)$ & $<0.001$ \\
\hline \multirow[t]{2}{*}{$\mathrm{N}$-stage } & No & Ref & Ref \\
\hline & N1 & $60.48(8.33-439.29)$ & $<0.001$ \\
\hline \multirow[t]{3}{*}{ Surgical procedure } & Lobectomy & Ref & \\
\hline & Subtotal or near-total thyroidectomy & $8.86(0.90-87.45)$ & 0.062 \\
\hline & Total thyroidectomy & $5.19(0.71-37.98)$ & 0.105 \\
\hline \multirow[t]{3}{*}{ Postoperative radioiodine treatment $(\mathrm{mCi})$} & None or refused & Ref & \\
\hline & Radiation beam or radioactive implants & $5.63(0.64-49.33)$ & 0.119 \\
\hline & $\begin{array}{l}\text { Radioisotopes or radiation beam + isotopes or } \\
\text { implants }\end{array}$ & $2.92(1.36-6.27)$ & 0.006 \\
\hline
\end{tabular}

factors for distant metastasis. Among these factors, age at diagnosis of $\leq 15$ years (odds ratio (OR) 0.29; 95\% confidence interval (CI) $0.14-0.61$ ) and N1 stage (OR 36.98; 95\% CI 4.07-336.25) were risk factors for increased incidence of distant metastasis. Higher T-stage also increased the risk of distant metastasis (T2, OR 0.81, 95\% CI 0.19-3.49; T3, OR 4.06, 95\% CI 1.10-15.02; T4, OR 23.51, 95\% CI 4.85-113.96). However, sex, race, year of diagnosis, pathological type, number of tumor foci, tumor extension, surgical procedure and radiation were not independent predictors of distant metastasis (Tables 3 and 4).

Meanwhile, $1.73 \%$ of patients aged $>15$ years had distant metastasis, whereas $6.73 \%$ of patients aged $\leq 15$ years had distant metastasis. This provides evidence of a higher risk of metastasis in younger pediatric thyroid cancer patients. Furthermore, higher N-stage and T-stage were associated with a higher probability of distant metastasis (Tables 5, 6 and 7). There were 49 patients with distant metastasis who exhibited lymph node metastasis, whereas there was only one patient without lymph node metastasis.

However, there were only seven cases of all-cause mortality and three cases of cancer-specific mortality.
These numbers were too low to evaluate the hazard ratios (Supplementary Tables 1, 2, 3 and 4, see section on supplementary data given at the end of this article). However, cancer-specific mortality for T-stage was statistically significant in a Kaplan-Meier survival curve $(P=0.024)$, whereas all-cause mortality was not significant. Moreover, a log-rank test also demonstrated no statistically significant difference between the overall survival or cancer-specific survival curves based on age at diagnosis and N-stage (Figs 1, 2 and 3).

\section{Discussion}

The risk for thyroid cancer is much higher in the pediatric population compared with that in adults (7), and nodules self-discovered by families represent $41 \%$ of diagnosed cases. Of these, 64\% had lymph node metastasis, and $7 \%$ had pulmonary metastasis (8), indicating that distant metastasis at first prognosis comprises a large percentage of differentiated pediatric thyroid cancer. Even though the prognosis of most children with thyroid cancer is favorable (9), early detection improves outcome (10) and may help decrease the obligate risks of aggressive 
Table 4 Odds ratio for distant metastasis: outcome of multivariate logistic regression.

\begin{tabular}{|c|c|c|c|}
\hline \multirow[b]{2}{*}{ Covariate } & \multirow[b]{2}{*}{ Level } & \multicolumn{2}{|c|}{ Distant metastasis } \\
\hline & & Odds ratio $(95 \% \mathrm{Cl})$ & $P$-value \\
\hline \multirow[t]{2}{*}{ Gender } & Female & Ref & \\
\hline & Male & $0.82(0.35-1.89)$ & 0.635 \\
\hline \multirow[t]{3}{*}{ Race } & White & Ref & \\
\hline & Black & $2.22(0.51-9.68)$ & 0.288 \\
\hline & Other & $0.67(0.18-2.47)$ & 0.552 \\
\hline Age at diagnosis & & $0.29(0.14-0.61)$ & 0.001 \\
\hline \multirow[t]{2}{*}{ Year of diagnosis } & 2004-2008 & Ref & \\
\hline & $2009-2013$ & $1.37(0.67-2.80)$ & 0.384 \\
\hline \multirow[t]{2}{*}{ Pathological type } & Papillary & Ref & \\
\hline & Follicular & $1.22(0.09-16.49)$ & 0.883 \\
\hline \multirow[t]{2}{*}{ Number of tumor foci } & 1 & Ref & \\
\hline & $\geq 2$ & $1.50(0.73-3.09)$ & 0.271 \\
\hline \multirow[t]{2}{*}{ Extension } & No & Ref & \\
\hline & Yes & $0.52(0.17-1.57)$ & 0.246 \\
\hline \multirow[t]{4}{*}{ T-stage } & $\mathrm{T} 1$ & Ref & \\
\hline & $\mathrm{T} 2$ & $0.81(0.19-3.49)$ & 0.776 \\
\hline & T3 & $4.06(1.10-15.02)$ & 0.036 \\
\hline & $\mathrm{T} 4$ & $23.51(4.85-113.96)$ & $<0.001$ \\
\hline \multirow[t]{2}{*}{ N-stage } & NO & Ref & \\
\hline & $\mathrm{N} 1$ & $36.98(4.07-336.25)$ & 0.001 \\
\hline \multirow[t]{3}{*}{ Surgical procedure } & Lobectomy & Ref & \\
\hline & Subtotal or near-total thyroidectomy & $0.46(0.02-9.13)$ & 0.609 \\
\hline & Total thyroidectomy & $0.41(0.04-4.83)$ & 0.481 \\
\hline \multirow[t]{3}{*}{ Radiation } & None or refused & Ref & \\
\hline & Radiation beam or radioactive implants & $3.50(0.21-57.24)$ & 0.379 \\
\hline & Radioisotopes or radiation beam + isotopes or implants & $1.27(0.46-3.54)$ & 0.643 \\
\hline
\end{tabular}

treatments required to treat advanced disease. Thus, improved understanding of distant metastasis will help improve surgical treatment and prognosis.

In the present study, there was a statistically significant positive relationship of distant metastasis with T-stage and N-stage among thyroid cancer patients aged 2-18 years. Moreover, there was a higher risk of metastasis in patients aged less than 15 years.

Distant metastasis is considered in the clinical diagnosis and medical treatment of other cancers such as cervical (11) and oropharyngeal (12). Therefore, distant metastasis might also help to establish guidelines for determining the use of thyroid surgery, specific treatments and follow-up of children with thyroid neoplasia. Furthermore, the present data suggest that age at diagnosis, T-stage and $\mathrm{N}$-stage should be considered in conjunction with distant metastasis.

Table 5 Association between age at diagnosis and distant metastasis in pediatric thyroid cancer patients.

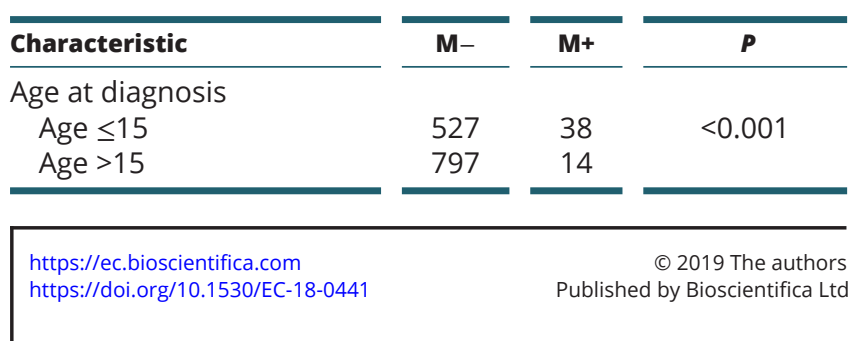

Age is generally considered as an important determinant of clinical outcome for differentiated thyroid cancer (13). Recent studies have evaluated the relationship between age at diagnosis and the prognosis of patients with differentiated thyroid cancer and suggest that patients aged $<20$ or $>70$ years have a poor prognosis, independent of cancer stage (14). In addition, studies are inconclusive regarding the relationship between age at diagnosis and cancer-specific death (15). The present study confirms that younger patients ( $\leq 15$ years) with thyroid cancer have a higher risk of distant metastasis than patients aged 16-18 years; further research is needed to corroborate and expound on this.

A previous study shows that for extrathyroidal growth to occur, the thyroid tumor must have reached a certain size, unless it arises from the periphery of the thyroid gland (16); this is consistent with the current results showing

Table 6 Association between N-stage and distant metastasis in pediatric thyroid cancer patients.
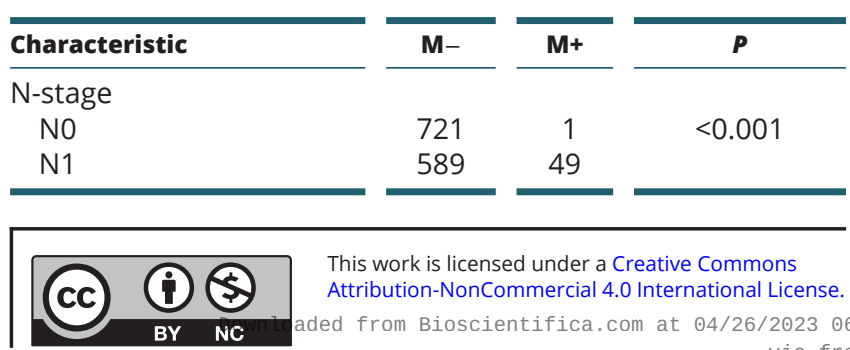

This work is licensed under a Creative Commons Attribution-NonCommercial 4.0 International License. ded from Bioscientifica.com at $04 / 26 / 2023$ 06:26:44AM via free access 
Table 7 Association between T-stage and distant metastasis in pediatric thyroid cancer patients.

\begin{tabular}{l}
\hline \\
\hline Distant metastasis \\
No. of patients (\%) \\
OR (95\% Cl) \\
$P$-value \\
\hline
\end{tabular}

\begin{tabular}{c}
\hline T1 \\
\hline 5/518 (0.97) \\
Ref
\end{tabular}

distant metastasis is more likely with higher T-stage. Moreover, previous studies point out that smaller thyroid cancers, which have not yet developed locoregional or distant metastases, are more often surgically curable (17). Furthermore, tumor size is also an important prognostic factor of lymph node metastasis (18). Accordingly, the present results may help to provide guidance regarding the appropriateness of surgery.

\section{Age at diagnosis $(n=1376)$}

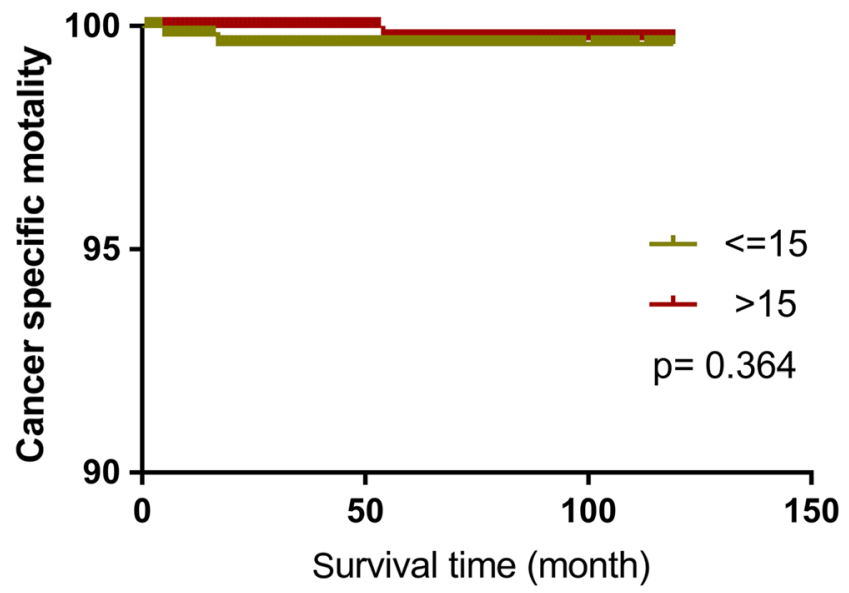

Age at diagnosis $(n=1376)$

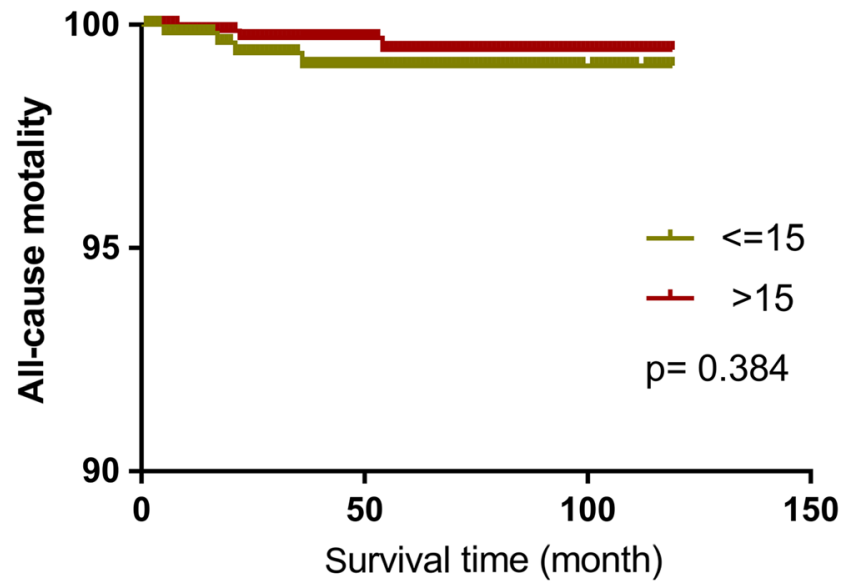

Figure 1

Kaplan-Meier curve based on age at diagnosis.
Compared with adults, younger patients are more likely to exhibit cervical lymph node metastasis (19), and previous studies suggest that carcinoma cells from the upper region are more likely to be transported to the lateral lymph nodes by lymphatic flow along the superior thyroid artery (20). Furthermore, metastasis to the Delphian node or to the lymph nodes in general is considered to indicate a risk factor for poor clinical outcome $(21,22,23)$.

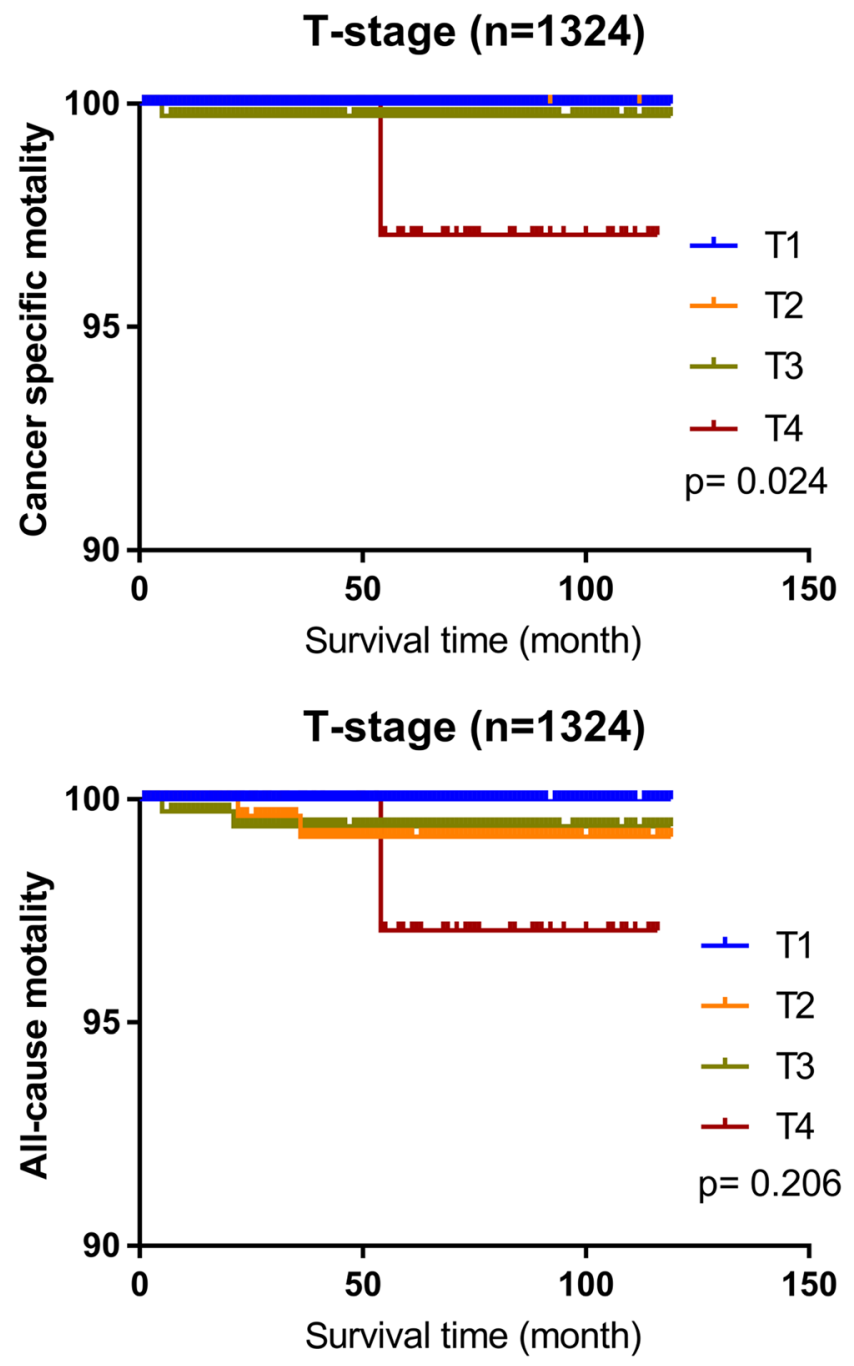

Figure 2

Kaplan-Meier curve based on T-stage.

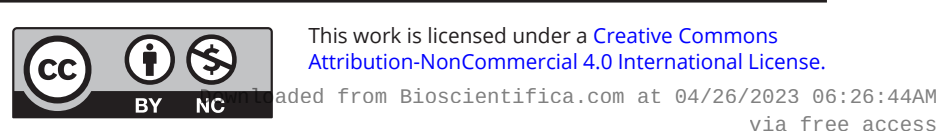


$N$-stage $(n=1366)$
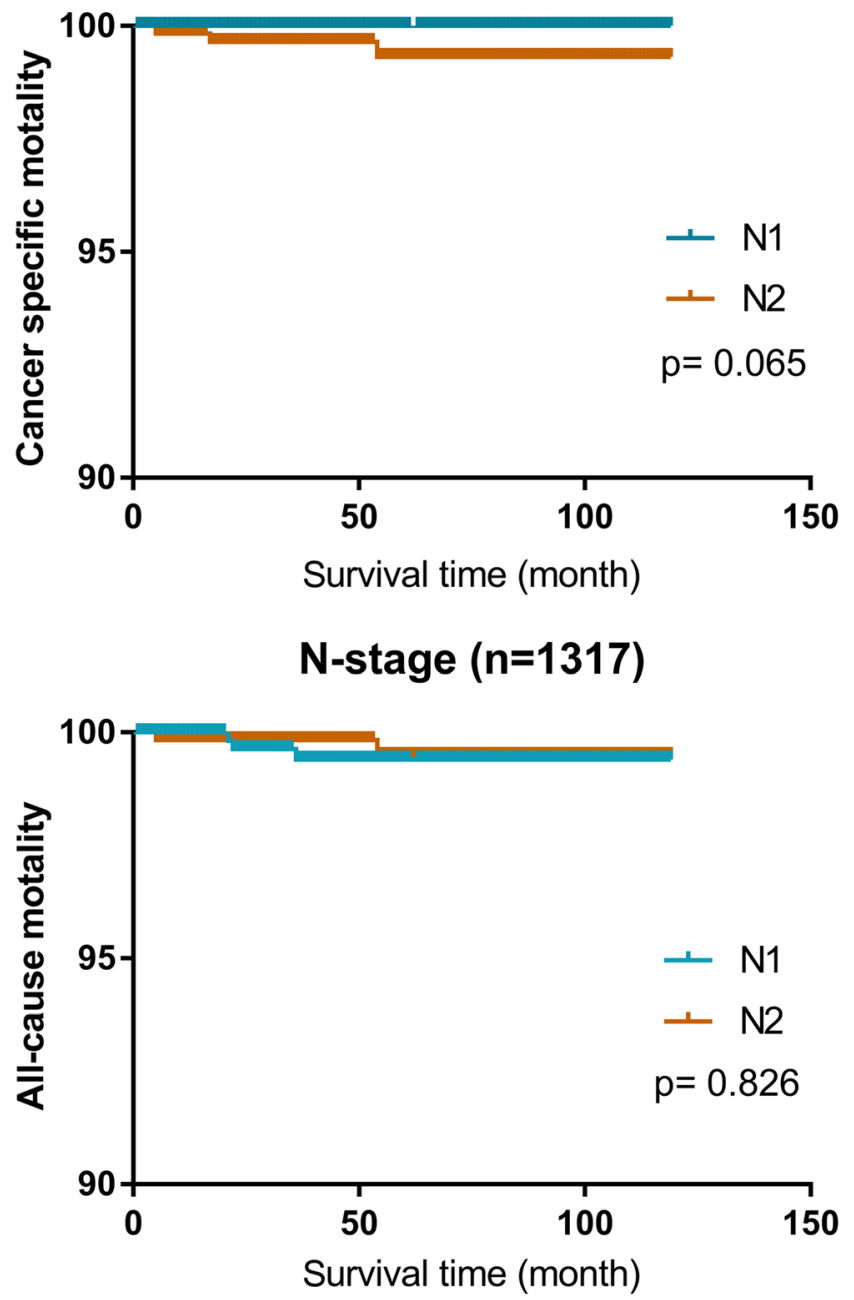

Figure 3

Kaplan-Meier curve based on N-stage.

However, there are limitations of the present study. Although a Kaplan-Meier analysis yielded significant results regarding T-stage and cancer-specific mortality, $\mathrm{N}$-stage and age at diagnosis were not significant; it is possible that we were unable to detect a difference due to insufficient data. Additionally, there was no significance for any factor with all-cause mortality. Moreover, cancerspecific mortality is typically not analyzed because prognosis of most children with thyroid cancer is favorable or the findings are limited because most series regarding differentiated thyroid cancer in children average only a 9-year follow-up. Another limitation is that we only analyzed factors influencing distant metastasis, thus we are unable to determine the specific region of transfer or the subsequent influences. In addition, potential confounding factors such as family history, vascular invasion and other factors related to selection bias were not in our analysis. Finally, inherent to the use of retrospective SEER data, the cases analyzed had heterogeneous management approaches over a relatively long-time period.

Hitherto, guidelines for diagnosis and treatment of children with thyroid cancer have not differed from those of adults. The objective of the current study was to determine factors that influence distant metastasis of pediatric thyroid cancer patients; these findings may help to provide data to support more specific guidelines for diagnosis and treatment of pediatric thyroid cancer patients and ultimately to improve prognosis.

\section{Supplementary data}

This is linked to the online version of the paper at https://doi.org/10.1530/ EC-18-0441.

\section{Declaration of interest}

The authors declare that there is no conflict of interest that could be perceived as prejudicing the impartiality of the research reported.

\section{Funding}

This work did not receive any specific grant from any funding agency in the public, commercial or not-for-profit sector.

\section{Author contribution statement}

All authors contributed to the design of the study and writing of the manuscript. W W, C Z, L Z, W Z, M W and H F F undertook the research, Y H H, S C C and W Z performed the analyses, Z M L and D H wrote the main manuscript text and prepared figures. All authors reviewed the manuscript.

\section{References}

1 Pacini F, Schlumberger M, Dralle H, Elisei R, Smit JW, Wiersinga W \& European Thyroid Cancer Taskforce. European consensus for the management of patients with differentiated thyroid carcinoma of the follicular epithelium. European Journal of Endocrinology 2006154 787-803. (https://doi.org/10.1530/eje.1.02158)

2 Xiong Y, Zhao Q, Li Z, Wang S, Guo H, Liu Z \& Huang T. Propensity score matching analysis of the prognosis for the rare oxyphilic subtype of thyroid cancer (Hurthle cell carcinoma). Oncotarget 20178 101362-101371. (https://doi.org/10.18632/oncotarget.20732)

3 Guo Y, Liu Z, Yu P, Liu C, Ming J, Zhang N, Yusufu M, Chen C $\&$ Huang T. Using foci number to predict central lymph node metastases of papillary thyroid microcarcinomas with multifocality. International Journal of Clinical and Experimental Medicine 20158 9925-9930.

4 Qu Y, Huang R \& Li L. Clinical analysis of the factors that influence disease progression of differentiated thyroid carcinoma in children. Journal of Paediatrics and Child Health 201753 903-907. (https://doi. org/10.1111/jpc.13569)

5 Francis GL, Waguespack SG, Bauer AJ, Angelos P, Benvenga S, Cerutti JM, Dinauer CA, Hamilton J, Hay ID, Luster M, et al. 
Management guidelines for children with thyroid nodules and differentiated thyroid cancer. Thyroid 201525 716-759. (https://doi. org/10.1089/thy.2014.0460)

6 Parisi MT, Eslamy H \& Mankoff D. Management of differentiated thyroid cancer in children: focus on the American Thyroid Association pediatric guidelines. Seminars in Nuclear Medicine 201646 147-164. (https://doi.org/10.1053/j.semnuclmed.2015.10.006)

7 Gupta A, Ly S, Castroneves LA, Frates MC, Benson CB, Feldman HA, Wassner AJ, Smith JR, Marqusee E, Alexander EK, et al. How are childhood thyroid nodules discovered: opportunities for improving early detection. Journal of Pediatrics 2014164 658-660. (https://doi. org/10.1016/j.jpeds.2013.10.090)

8 Waguespack SG \& Francis G. Initial management and follow-up of differentiated thyroid cancer in children. Journal of the National Comprehensive Cancer Network 20108 1289-1300. (https://doi. org/10.6004/jnccn.2010.0095)

9 Hung W \& Sarlis NJ. Current controversies in the management of pediatric patients with well-differentiated nonmedullary thyroid cancer: a review. Thyroid 200212 683-702. (https://doi. org/10.1089/105072502760258668)

10 American Thyroid Association Guidelines Taskforce on Thyroid N, Differentiated Thyroid C, Cooper DS, Doherty GM, Haugen BR, Kloos RT, Lee SL, Mandel SJ, Mazzaferri EL, McIver B, et al. Revised American Thyroid Association management guidelines for patients with thyroid nodules and differentiated thyroid cancer. Thyroid 2009 19 1167-1214. (https://doi.org/10.1089/thy.2009.0110)

11 Schmid MP, Franckena M, Kirchheiner K, Sturdza A, Georg P, Dorr W $\&$ Potter R. Distant metastasis in patients with cervical cancer after primary radiotherapy with or without chemotherapy and image guided adaptive brachytherapy. Gynecologic Oncology 2014133 256-262. (https://doi.org/10.1016/j.ygyno.2014.02.004)

12 Cho SW, Choi HS, Yeom GJ, Lim JA, Moon JH, Park DJ, Chung JK, Cho BY, Yi KH \& Park YJ. Long-term prognosis of differentiated thyroid cancer with lung metastasis in Korea and its prognostic factors. Thyroid 201424 277-286. (https://doi.org/10.1089/ thy.2012.0654)

13 Kim SJ, Myong JP, Suh H, Lee KE \& Youn YK. Optimal cutoff age for predicting mortality associated with differentiated thyroid cancer. PLoS One 201510 e0130848. (https://doi.org/10.1371/journal. pone.0130848)

14 Sharifi A, Shojaeifard A, Soroush A, Jafari M, Abdehgah AG \& Mahmoudzade H. Predictors of regional lymph node recurrence after initial thyroidectomy in patients with thyroid cancer. Journal of Thyroid Research 20162016 1-5. (https://doi. org/10.1155/2016/4127278)

15 Jonklaas J, Nogueras-Gonzalez G, Munsell M, Litofsky D, Ain KB, Bigos ST, Brierley JD, Cooper DS, Haugen BR, Ladenson PW, et al. The impact of age and gender on papillary thyroid cancer survival. Journal of Clinical Endocrinology and Metabolism 201297 E878-E887. (https://doi.org/10.1210/jc.2011-2864)

16 Machens A \& Dralle H. Decreasing tumor size of thyroid cancer in Germany: institutional experience 1995-2009. European Journal of Endocrinology 2010163 111-119. (https://doi.org/10.1530/EJE-100203)

17 Pellegriti G, Scollo C, Lumera G, Regalbuto C, Vigneri R \& Belfiore A. Clinical behavior and outcome of papillary thyroid cancers smaller than $1.5 \mathrm{~cm}$ in diameter: study of 299 cases. Journal of Clinical Endocrinology and Metabolism 200489 3713-3720. (https://doi org/10.1210/jc.2003-031982)

18 Lim YS, Lee JC, Lee YS, Lee BJ, Wang SG, Son SM \& Kim IJ. Lateral cervical lymph node metastases from papillary thyroid carcinoma: predictive factors of nodal metastasis. Surgery 2011150 116-121. (https://doi.org/10.1016/j.surg.2011.02.003)

19 Landau D, Vini L, A'Hern R \& Harmer C. Thyroid cancer in children: the Royal Marsden Hospital experience. European Journal of Cancer 200036 214-220. (https://doi.org/10.1016/S09598049(99)00281-6)

20 Ito Y, Kobayashi K, Tomoda C, Uruno T, Takamura Y, Miya A, Matsuzuka F, Kuma K \& Miyauchi A. Ill-defined edge on ultrasonographic examination can be a marker of aggressive characteristic of papillary thyroid microcarcinoma. World Journal of Surgery 200529 1007-1011; discussion 1011-1002. (https://doi. org/10.1007/s00268-005-7834-9)

21 Iyer NG, Kumar A, Nixon IJ, Patel SG, Ganly I, Tuttle RM, Shah JP \& Shaha AR. Incidence and significance of Delphian node metastasis in papillary thyroid cancer. Annals of Surgery 2011253 988-991. (https://doi.org/10.1097/SLA.0b013e31821219ca)

22 Noguchi S, Murakami N, Yamashita H, Toda M \& Kawamoto H. Papillary thyroid carcinoma: modified radical neck dissection improves prognosis. Archives of Surgery 1998133 276-280. (https:// doi.org/10.1001/archsurg.133.3.276)

23 Ortiz S, Rodriguez JM, Soria T, Perez-Flores D, Pinero A, Moreno J \& Parrilla P. Extrathyroid spread in papillary carcinoma of the thyroid: clinicopathological and prognostic study. OtolaryngologyHead and Neck Surgery 2001124 261-265. (https://doi.org/10.1067/ mhn.2001.113141)

Received in final form 3 January 2019

Accepted 8 January 2019

Accepted Preprint published online 8 January 2019 https://ec.bioscientifica.com https://doi.org/10.1530/EC-18-0441 (c) 2019 The authors Published by Bioscientifica Ltd

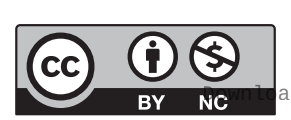

This work is licensed under a Creative Commons Attribution-NonCommercial 4.0 International License. ded from Bioscientifica.com at 04/26/2023 06:26:44AM 